\title{
ANALISIS ROUTING RESERVOIR DALAM PENGEMBANGAN SUMBER DAYA AIR KAWASAN KARST
}

\author{
Rr Diah Nugraheni Setyowati ${ }^{1}$, Rahmad Junaidi ${ }^{2}$ \\ ${ }^{1}$ Teknik Lingkungan, Universitas Islam Negeri Sunan Ampel, Jl. Jend. A. Yani 117 Surabaya \\ Email: diahnugraheni@uinsby.ac.id \\ ${ }^{2}$ Arsitektur, Universitas Islam Negeri Sunan Ampel, Jl. Jend. A. Yani 117 Surabaya \\ Email: junaichi@yahoo.co.id
}

\begin{abstract}
ABSTRAK
Pengembangan sumberdaya air adalah upaya peningkatan kemanfaatan fungsi sumber daya air tanpa merusak keseimbangan lingkungan. Pengembangan Sumber Daya Air didalam Hukum Tata Lingkungan tercakup pada azas ke 13 yaitu azas penyelenggaraan kepentingan umum (principle of public service). Adapun Pengembangan Sumber Daya Air didalam Ilmu Lingkungan tercakup pada azas ke tiga atau Hukum Termodinamika ke tiga ialah menyangkut sumber alam, meliputi materi, ruang, waktu, dan keanekaragaman (Tresna, 2000). Kawasan karst memiliki karakteristik relief dan drainase yang khas, terutama disebabkan oleh larutnya batuan yang tinggi di dalam air, jika dibandingkan dengan daerah lain. Pada kawasan ini dapat diketahui yaitu relief pada bentang alam ini berada pada kawasan yang berbatuan yang mudah larut, juga dapat diketahui dengan adanya aliran sungai yang secara tiba tiba masuk tanah meninggalkan lembah kering dan muncul sebagai mata air yang besar. Pada kawasan ini pola pengaliran tidak sempurna, kadang tampak, kadang hilang, yang disebut sebagai sungai bawah tanah. Kawasan karst terbentuk dari tanah karst yang didominasi oleh batu gamping. Menurut Bowles (1989), klasifikasi batu gamping termasuk batuan sedimentasi kimiawi terdiri dari kalsit (CaCO3), yang mempunyai sifat cepat bereaksi dengan cairan asam (hydroclorida). Tanah karst termasuk kategori tanah yang tidak mendukung keberadaan air permukaan, karena tanah tersebut tersusun dari batuan karbonat terutama $\mathrm{CaCO} 3$ dan dolomit $\mathrm{CaMg}$ (CO3)2. Metode Penelitian yang digunakan adalah metode deskriptif kualitatif, yang bertujuan memberikan gambaran sistematis terhadap obyek penelitian. Sistem pendistribusian air direncanakan dalam sistem jaringan dengan cara gravitasi. Sistem gravitasi bertujuan akan memperlancar pendistribusian air ke konsumen dengan dampak biaya operasional relatif ringan. Metode perhitungan yang digunakan dengan analisis routing reservoir. Dari hasil analisis, untuk dapat melayani semua konsumen +75.000 orang maka RB-2 memerlukan debit inflow minimum 86 1/dt. Bila debit minimum ke RB-2 65 1/dt baru dapat melayani $65 \%$ dari kebutuhan air total. Sedangkan untuk debit inflow minimum 82 1/dt baru dapat melayani $91 \%$ kebutuhan air total.
\end{abstract}

Kata kunci: pengembangan, sumberdaya air, routing reservoir, karst.

\section{PENDAHULUAN}

\section{Latar Belakang}

Air adalah semua air yang terdapat pada, di atas, ataupun di bawah permukaan tanah, termasuk dalam pengertian ini air permukaan, air tanah, air hujan dan air laut yang berada di darat. Pada saat ini $76 \%$ dari penduduk dunia memiliki ketersediaan air kurang dari $5.000 \mathrm{~m}^{3}$ per kapita per tahun dan $35 \%$ penduduk mendapatkan pasokan air yang sangat rendah. Situasi ini akan semakin memburuk di awal abad berikutnya, yaitu pada tahun 2025 sebagian besar penduduk bumi akan hidup di dalam kondisi kekurangan air (Shiklomanov, 1998). Total volume air di bumi berjumlah 1.400 juta $\mathrm{km}^{3}$, dimana hanya $2,5 \%$, atau sekitar 35 juta $\mathrm{km}^{3}$ adalah air. Sebagian air dalam bentuk permanen seperti es dan salju, terperangkap di Antartika dan Greenland, atau dalam air bawah tanah. Sumber air yang dimanfaatkan manusia adalah sungai, danau, embun yang berada di tanah, dan air bawah tanah yang membentuk kolam. Porsi pemanfaatan sumber ini hanya sekitar $200.000 \mathrm{~km}^{3}$ dari jumlah air yang tersedia kurang dari $1 \%$ dari jumlah air dan hanya $0,01 \%$ dari jumlah air yang berada di bumi (Shiklomanov, 1993). 
Manusia sebagai masyarakat pengguna air umumnya berpendapat bahwa, keberadaan air secara alami tersedia dalam jumlah yang cukup untuk memenuhi kebutuhan hidupnya. Kenyataannya ketersediaan / keberadaan air saat ini menurut ruang dan waktu tidak sesuai dengan yang dikehendaki manusia. Hal ini disebabkan antara lain karena kerusakan Daerah Aliran Sungai (DAS) nya, kebutuhan air bersih meningkat dan jenis tanah. Ada jenis tanah yang kurang mendukung keberadaan air tersebut, antara lain tanah karst. Pasokan air dalam jumlah yang besar, berasal dari air hujan. Air yang jatuh ke bumi akan terdistribusi dalam bentuk air permukaan, kemudian air limpasan permukaan dan air bawah permukaan tanah. Air bawah permukaan tanah terjadi karena proses rembesan yang melalui tanah yang porus. Besar kecilnya rembesan dipengaruhi oleh koefisien rembesan (k). Proses rembesan air yang sangat tinggi akan berakibat air permukaan tidak tertampung dengan baik. Timbullah ketidakseimbangan antara kebutuhan air yang meningkat dengan ketersediaan air yang relatif sedikit. Oleh karena itu ketidak seimbangan ini menyebabkan terjadinya kekurangan air atau krisis air di kawasan karst, terutama di musim kemarau.

\section{Pengembangan Sumber Daya Air}

Sumber air adalah tempat atau wadah air alami dan/atau buatan yang terdapat pada, di atas, ataupun di bawah permukaan tanah. Daya air adalah potensi yang terkandung dalam air dan / atau pada sumber air yang dapat memberikan manfaat ataupun kerugian bagi kehidupan dan penghidupan manusia serta lingkungannya. Pengembangan sumberdaya air adalah upaya peningkatan kemanfaatan fungsi sumber daya air tanpa merusak keseimbangan lingkungan. Pengembangan Sumber Daya Air didalam Hukum Tata Lingkungan tercakup pada azas ke 13 yaitu azas penyelenggaraan kepentingan umum (principle of public service). Adapun Pengembangan Sumber Daya Air didalam ilmu lingkungan tercakup pada azas ke tiga atau Hukum Termodinamika ke tiga ialah menyangkut sumber alam, meliputi materi, ruang, waktu, dan keanekaragaman (Tresna, 2000).

Pengembangan Sumber Daya Air meliputi penataan, penyediaan, penggunaan, pengembangan dan pengusahaan sumber daya air. Tujuan untuk memanfaatkan sumber daya air secara berkelanjutan dengan mengutamakan pemenuhan kebutuhan pokok kehidupan masyarakat secara adil. Mengutamakan fungsi sosial dengan memperhatikan prinsip pemanfaatan air. Biaya jasa pengelolaan sumber daya air melibatkan peran masyarakat (UU RI No. 7, 2004). Permasalahan sumber daya air dapat ditinjau dari sisi pasokan / ketersediaan, sisi penggunaan dan sisi manajemen. Adapun visi pengelolaan sumber daya air ialah terwujudnya kemanfaatan sumber daya air bagi kesejahteraan seluruh rakyat. Adapun misi pengelolaan sumber daya air ialah:
a. Konservasi sumber daya air.
b. Pendayagunaan sumber daya air.
c. Pengendalian dan penanggulangan daya rusak air.
d. Pemberdayaan dan peningkatan peran masyarakat, swasta dan pemerintah
e. Peningkatan ketersediaan data dan informasi Sumber Daya Air, termasuk sistem prasarana dan sarananya (Soenarno, 2003).

\section{Karakteristik Kawasan Karst}

Pengertian karst secara luas adalah bentuk bentang alam khas yang terjadi akibat proses pelarutan pada suatu kawasan batuan karbonat atau batuan mudah terlarut (umumnya formasi batu gamping) sehingga menghasilkan berbagai bentuk permukaan bumi yang unik dan menarik dengan ciri-ciri khas exokarst (di atas permukaan) dan indokarst (di bawah permukaan). Penggunaan istilah karst secara internasional berawal dari bahasa Jerman yang diserap dari bahasa Slavia kras yang memiliki arti lahan gersang berbatu. Istilah kras diberikan untuk wilayah di Serbia, Bosnia, Herzegovina, Slovenia, Albania (dahulu Yugoslavia) yang memiliki topografi khas akibat proses pelarutan pada batuannya. Di beberapa negara penggunaan istilah bentang alam unik ini beragam misalnya karst (Jerman dan Inggris), carso (Italia), kras (negara-negara Balkan), karusuto (Jepang), atau kars (Malaysia). Sedangkan di Indonesia pernah diperkenalkan dengan istilah kras atau curing (Hadiwidjojo, 1994).

Kawasan Karst memiliki karakteristik relief dan drainase yang khas, terutama disebabkan oleh larutnya batuan yang tinggi di dalam air, jika dibandingkan dengan daerah lain. Pada kawasan ini dapat diketahui yaitu relief pada bentang alam ini berada pada kawasan yang berbatuan yang mudah larut, juga dapat diketahui dengan adanya aliran sungai yang secara tiba tiba masuk tanah meninggalkan lembah kering dan muncul sebagai mata air yang besar. Pada kawasan ini pola pengaliran tidak sempurna, kadang tampak, kadang hilang, yang disebut sebagai sungai bawah tanah. Ciri-ciri khusus dari kawasan karst antara lain:

a. Terdapatnya sejumlah cekungan (depresi) dengan bentuk dan ukuran yang bervariasi, cekungan tersebut digenangi air atau tanpa air dengan kedalaman dan jarak yang berbeda-beda.

b. Bukit-bukit kecil dalam jumlah banyak yang merupakan sisi-sisi erosi akibat pelarutan kimia pada batu gamping, sehingga terbentuk bukit-bukit (conical hills). 
c. Sungai-sungai tidak mengalami perkembangan pada permukaan. Sungai pada kawasan karst umumnya terputus-putus, hilang kedalam tanah dan begitu saja muncul dari dalam tanah.

d. Terdapatnya sungai-sungai bawah tanah (di bawah permukaan) dan adanya goa-goa kapur pada permukaan atau di atas permukaan.

e. Terdapatnya endapan sedimen lumpur berwarna merah (terrarosa) yang merupakan endapan resedual akibat pelapukan batu gamping.

f. Permukaan yang terbuka mempunyai kenampakan yang kasar, pecah-pecah atau lubang-lubang mapun runcing-runcing (lapies).

g. Banyaknya Stalaktit dan Stalakmit akibat dari air yang masuk ke lubang-lubang (doline) kemudian turun ke gua dan menetes dari atap gua ke dasar gua yang berubah jadi batuan.

Kawasan karst merupakan kawasan yang terbentuk dari tanah karst dan umumnya berada di perbukitan atau kawasan yang berbukit-bukit dan tanahnya didominasi oleh batu gamping (limestone). Menurut Bowles (1989), klasifikasi batu gamping termasuk batuan sedimentasi kimiawi. Batuan tersebut terdiri dari kalsit (CaCO3),yang mempunyai sifat cepat bereaksi dengan cairan asam (hidroclorida). Tanah karst termasuk kategori tanah yang tidak mendukung keberadaan air permukaan, karena tanah tersebut tersusun dari batuan karbonat terutama $\mathrm{CaCO} 3$ dan dolomit $\mathrm{CaMg}$ (CO3)2. Sifat dari batu gamping (CaCO3) yang mendominasi tanah karst, mempunyai daya / tingkat kelarutan tinggi, sehingga tanah menjadi porus. Hal ini mengakibatkan terjadinya banyak rekahan (cavities), lubang-lubang pada batuan, luweng (shinkhole), gua dan bukit.

Air tanah di kawasan karst umumnya mempunyai sifat khusus. Keberadaan air tanah tersebut banyak dijumpai pada rongga-rongga, celah-celah batuan dan pada luweng. Proses rembesan air yang sangat tinggi di tanah karst, berakibat air permukaan tidak dapat tertampung dengan baik. Ini menimbulkan ketidakseimbangan antara peningkatan kebutuhan air dengan ketersediaan air yang relatif sedikit.

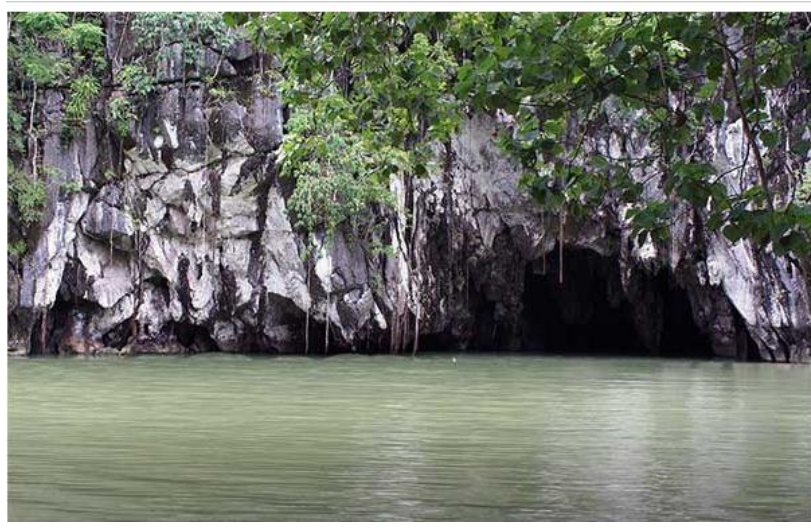

Gambar 2.1. Kawasan Karst dengan Sungai Bawah Tanah

Di Indonesia banyak terdapat kawasan karst, diperkirakan memiliki kawasan batuan karbonat yang luasnya mencapai 15,4 juta hektar yang tersebar di beberapa wilayah di Indonesia mulai dari barat hingga timur. Beberapa kawasan tersebut telah dikembangkan sebagai kawasan kars bahkan telah menjadi Geopark pertama di Indonesia untuk kawasan kars Gunungsewu (Jawa Tengah - Jawa Timur) dan secara aklamasi oleh International Union of Speleoloogy dinyatakan sebagai World Natural Heritage. Berikut adalah beberapa kawasan karst di Indonesia:

a. Gunung Leuser (Aceh)

b. Perbukitan Bohorok (Sumut), Payakumbuh (Sumbar)

c. Bukit Barisan, mencakup Baturaja (Kabupaten Ogan Kombering Ulu)

d. Sukabumi selatan (Kawasan Jawa Barat)

e. Kawasan Karst Gombong Selatan, Kebumen (Jawa Tengah)

f. Pegunungan Kapur Utara, mencakup daerah Kudus, Pati, Grobogan, Blora dan Rembang Jawa Tengah)

g. Pegunungan Kendeng, Kawasan Jawa Timur

h. Pegunungan Sewu, yang membentang dari Kabupaten Bantul di barat hingga Kabupaten Tulungagung.

i. Sistem perbukitan Blambangan, Jawa Timur

j. Perbukitan di bagian barat Pulau Flores, tempat lokasi banyak gua, salah satu di antaranya adalah Liang Bua (Nusa Tenggara Timur, NTT)

k. Perbukitan karst Sumba (NTT) 
1. Pegunungan karst Timor Barat (NTT) Kawasan Pegunungan Sangkulirang - Tanjung Mangkaliat seluas 293.747,84 hektare, memiliki gua-gua dengan lukisan dinding manusia purba (Kalimantan Timur)

m. Perbukitan Maros Pangkajene, terletak di Kabupaten Maros dan Kabupaten Pangkep Sulawesi Selatan, seluas 4.500 hektare dan beberapa di antara gua-gua yang ada memiliki lukisan purba

n. Kawasan karst Wowolesea, memiliki sistem air asin hangat (Sulawesi Tenggara)

o. Pulau Muna

p. Kepulauan Tukangbesi

q. Pulau Seram (Maluku)

r. Pulau Halmahera (Maluku Utara)

s. Kawasan karst Fakfak (Papua Barat)

t. Pulau-pulau Biak dan Pegunungan Tengah dan Pegunungan Lorentz (Papua)

u. Kawasan Batu Hapu, Tapin, Kalimantan Selatan

v. Pegunungan Schwaner (Kalbar), dll

Salah satu kawasan karst yang menjadi fokus penelitian ini adalah Kawasan Karst di Pegunungan Sewu, Kabupaten Gunung Kidul, dimana pada kawasan tersebut terdapat Sungai Bawah Tanah Bribin. Dari hasil penelitian sebelumnya, diperoleh data bahwa debit air Sungai Bawah Tanah Bribin berkisar antara 956 1/dt - 1500 1/dt. Besar debit sungai tersebut, merupakan acuan atau dasar bagi pemerintah dalam hal ini PDAM Gunung Kidul untuk menyatakan bahwa air Sungai Bawah Tanah Bribin, merupakan sumber air yang signifikan untuk mengatasi kekeringan yang terjadi di wilayah Bribin. Hal ini yang menjadi acuan PDAM Gunung Kidul untuk memanfaatkan air sungai Bribin untuk menangani kekurangan pasokan air. Kemudian dibuat bendung (weir) di Sungai Bawah Tanah Bribin, dengan debit yang diambil 60 l/dt menggunakan pompa dan booster pump. Namun karena pertumbuhan penduduk yang begitu pesat mengakibatkan dalam pelaksanaannya belum dapat memenuhi seluruh penduduk. Oleh karena itu diperlukan perhitungan ulang untuk memperbesar debit pengambilan agar semua penduduk dapat memperoleh pasokan air.

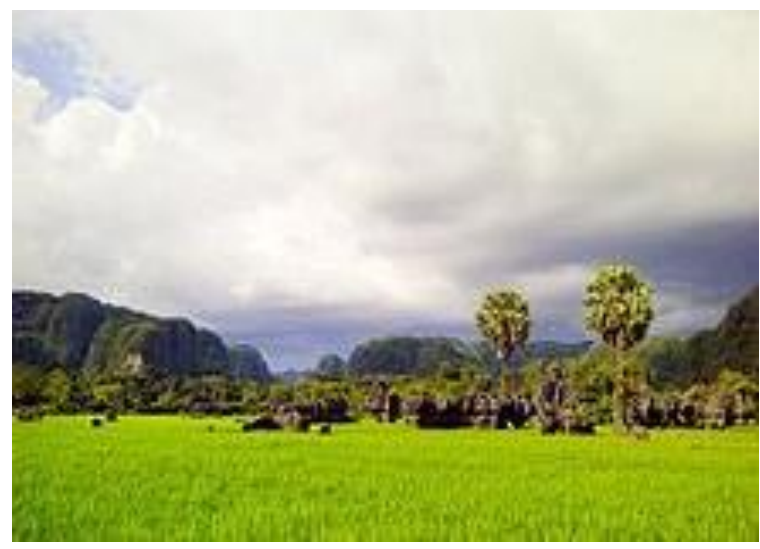

Gambar 2.2. Pegunungan Kars

\section{Analisis Routing Reservoir}

Usaha untuk memperoleh debit yang lebih besar, dilakukan oleh pemerintah bekerjasama dengan Universitat Karlsruhe. Pengambilan debit sebesar 80 1/dt didapat dengan menggunakan bendungan (barrage) baru yang berada di Sungai Bawah Tanah Bribin bagian hilir (BR II). Untuk menaikkan air dengan debit 80 1/dt ke reservoir baru di Kaligoro (RB-2) pada elevasi +406.225 m, digunakan teknologi mikro hidro Turbin - Pompa. Reservoir di Kaligoro (RB-2) yang terletak dengan beda tinggi +441 m dari muka air sungai, diperkirakan merupakan tempat tampungan yang cukup tinggi terhadap jaringan air bersih sub sistem Bribin. Sistem pendistribusian air direncanakan dalam bentuk sistem jaringan dengan cara gravitasi. Sistem gravitasi bertujuan akan memperlancar pendistribusian air ke konsumen dan dampaknya beaya operasional relatif ringan. Untuk mengetahui seberapa besar kemampuan debit 80 1/dt, dalam melayani konsumen yang ada maka dilakukan suatu penelitian. Metode perhitungan yang digunakan dengan cara analisis routing reservoir.

Untuk memprediksi besarnya debit inflow yang masuk ke reservoir, diperlukan analisis routing reservoir yang dimulai dari reservoir yang langsung untuk melayani konsumen. Selanjutnya dilakukan routing ke reservoir yang mensuplai reservoir awal, dan seterusnya sampai pada reservoir utama. Penelusuran (routing) pada reservoir dilakukan untuk menganalisis kebutuhan air yang masuk ke reservoir. Ketersediaan reservoir dengan volume tertentu diprediksi agar dapat menampung air sesuai dengan kebutuhan. Turunnya muka air dalam tangki tergantung pada 
luasan tangki (reservoir), selisih antara pengambilan dan suplai serta lamanya waktu puncak. Waktu puncak yaitu saat pengambilan lebih besar dari suplai. Perencanaan reservoir didasarkan atas daya tampung air, sebesar kekurangan kebutuhan air antara suplai dan saat jam puncak. Kekurangan air tidak boleh kurang dari elevasi minimum dalam reservoir. Hubungan antara pertambahan atau pengurangan volume reservoir oleh pengambilan dan suplai dapat ditulis dalam bentuk rumus (dalam Radianto, 2000). Lebih rinci, dengan memasukkan faktor waktu t, menjadi:

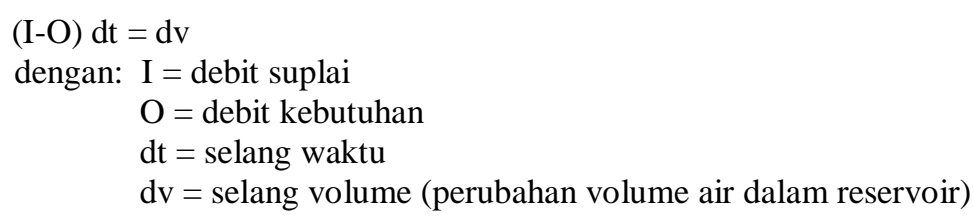

Menurut pedoman / petunjuk teknik dan manual pada sistem penyediaan air di pedesaan, maka penampungan dan pengukuran volume air dengan mengukur lamanya air yang mengisi reservoir (t), dengan volume tertentu adalah

Debit air $(\mathrm{Q})=$ vol. penampungan / $\mathrm{t}(\mathrm{l} / \mathrm{dt})$

Besarnya debit, karena penambahan muka air $(\mathrm{H})$ dalam reservoir yang mempunyai luas (A) dalam jangka waktu tertentu (t) adalah:

$$
\mathrm{Q}=\frac{H \times \mathrm{A}}{\mathrm{t}} 1 / \mathrm{dt}
$$

Kapasitas reservoir adalah kapasitas seluruh ruang dalam reservoir tanpa ruang lumpur. Adapun tinggi bebas $+2 \mathrm{~cm}$ dan tinggi muka air minimum $+30 \mathrm{~cm}$ (Kimpraswil, 2002:117).

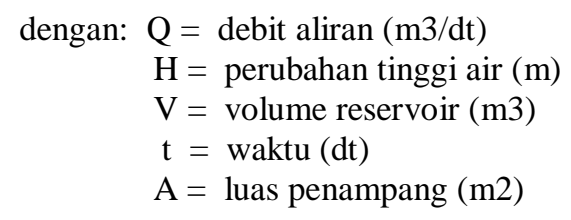

\section{METODE PENELITIAN}

Metode Penelitian yang digunakan adalah metode deskriptif kualitatif, yang bertujuan memberikan gambaran secara sistematis terhadap obyek yang diteliti. Penelitian ini merupakan penelitian yang memanfaatkan data-data yang sudah ada. Dari data yang di peroleh kemudian di analisis, dimana analisis tersebut untuk menentukan fenomena yang diteliti dan mencari pemecahannya. Data yang dikumpulkan meliputi data sekunder dan data primer. Data sekunder diperoleh dari buku-buku referensi, jurnal, karya tulis yang relevan dengan penelitian ini. Data primer diperoleh dari hasil observasi yang dilakukan dengan pengamatan langsung mengenai kondisi dan situasi di lokasi penelitian. Penelitian ini dilakukan didaerah tangkapan Bribin yang terdapat di daerah karst Pegunungan Seribu (Gunung Sewu) bagian barat wilayah Kabupaten Gunung Kidul. Gunung Sewu terhampar memanjang di Pulau Jawa bagian selatan dan sebagian menempati bagian selatan Kabupaten Gunung Kidul. Lokasi penelitian pertama di kawasan karst Gunung Kidul sub sistem Bribin dan lokasi penelitian selanjutnya di lingkup shaft, rencana konstruksi barrage dan turbin pompa di sub sistem Bribin.

\section{HASIL DAN PEMBAHASAN}

Untuk memprediksi debit inflow yang masuk ke masing-masing reservoir, diperlukan analisis dengan cara penelusuran (routing) pada reservoir tersebut. Routing dimulai dari reservoir yang langsung untuk melayani konsumen. Selanjutnya dilakukan routing ke reservoir yang mensuplai reservoir awal, dan seterusnya sampai pada reservoir utama. Penelusuran (routing) pada reservoir dilakukan untuk menganalisis kebutuhan air yang masuk ke reservoir. Ketersediaan reservoir dengan volume tertentu diprediksi agar dapat menampung air sesuai dengan kebutuhan. Kebutuhan air didasarkan oleh volume minimum, yang terkait dengan akan digunakannnya sistem jaringan distribusi air yang baru. Alternatif-I berupa perhitungan debit inflow minimum yang diperlukan oleh R-4 bila distribusi air dari R-4 langsung ke R-7.

Besarnya debit minimum atau I minimum pada masing-masing reservoir dari hasil perhitungan perlu dicheck lagi. Hal ini dilakukan dengan maksud untuk mengetahui apabila debit minimum yang ada memenuhi kriteria atau tidak. Caranya dengan perhitungan inflow-outflow, yang disajikan dalam bentuk tabulasi dan grafik hubungan inflow- 
outflow dari masing-masing reservoir. Perhitungan yang ditampilkan hanya untuk reservoir RB-2, R-4, R-5 dan R-8 yang dianggap cukup mewakili. Dari hasil perhitungan terdapat kelebihan air. Kelebihan air yang terjadi merupakan cadangan bila terjadi kekurangan air pada pemakaian saat jam puncak. Perhitungan inflow-outflow dari reservoir RB2, R-4, R-5 dan R-8.

Besarnya inflow dan outflow ditetapkan dalam satuan liter/hari dengan jam pemakaian selama 24 jam. Didalam perhitungan kebutuhan total air pada RB-2, 1 Sambungan Rumah (SR) dengan asumsi untuk melayani 5 orang dan standar pemakaian air maksimum dipakai 90 1/org/hari. Kemudian 1 Hidran Umum (HU) dengan asumsi untuk melayani 100 orang dan standar pemakaian air sebesar 30 1/orang/hari. Pada R-4, R-5 dan R-6 standar pemakaian air diambil masing-masing sebesar 65 1/org/hari. Perhitungan outflow adalah prosentase dikalikan kebutuhan total air. Adapun perhitungan besarnya inflow adalah jumlah pemakaian (dalam jam) dikalikan dengan besarnya inflow minimum.

Dari hasil penelitian, reservoir baru di RB-2 dengan el. $+406.225 \mathrm{~m}$ dijadikan sebagai reservoir utama. Air yang ditampung berasal dari SBT Bribin dengan teknologi mikro-hidro turbin pompa. Pemompaan air ke RB-2 melalui pipa transmisi yang terdapat pada shaft. Kedalaman shaft dari muka tanah sampai ke SBT Bribin $+102 \mathrm{~m}$. Pendistribusian air dari RB-2 ke konsumen dengan sistem jaringan distribusi air bersih baru. Outflow dari RB-2 ke R4, R-5 dan R-8 dengan pertimbangan yaitu bila ditinjau dari elevasi antara RB-2 dengan elevasi R-4, R-5 dan R-8, maka dapat dilakukan cara gravitasi. Jarak RB-2 ke 3 reservoir tersebut relatif dekat dan kondisi lahan tempat rencana jaringan pipa, tidak begitu sulit.

Dari R-4, yang didistribusikan ke R-2, R-6, menggunakan jaringan pipa lama. Dari R-4 ke R-2 melalui R-3 dengan cara gravitasi. Dari R-3 ke R-2 dengan dibantu pompa. Untuk ke R-6, karena elevasi R-6 lebih tinggi dari R-4, maka perlu dibantu pompa dan booster -pump yang sudah ada. Dari R-6 ke R-9, dan ke R-7 karena ada kenaikan elevasi, maka dibantu dengan booster-pump. Dari R-5, didistribusikan ke 10 desa, menggunakan jaringan pipa lama dengan cara gravitasi yang dibantu oleh beberapa BPT. Dari R-8 didistribusikan ke 6 desa, dengan menggunakan jaringan pipa lama. Karena sebagian besar elevasi permukiman lebih tinggi dari elevasi R-8, maka perlu dibantu dengan booster-pump dan sebagian kecil dengan cara gravitasi. Sistem jaringan pipa distribusi air bersih lama yang masih digunakan yaitu dari R-4 ke R-2 dan R-6 kemudian dari R-6 ke R-7 dan R-9. Pendistribusian air menggunakan pompa dan booster pump. Jadi sistem jaringan pipa distribusi air bersih yang baru adalah penggabungan (connect) antara sistem jaringan pipa distribusi air bersih yang menggunakan cara gravitasi dengan sistem jaringan pipa distribusi air lama yang masih digunakan.

\section{KESIMPULAN}

Dari hasil penelitian, reservoir baru di RB-2 dengan el. $+406.225 \mathrm{~m}$ dijadikan sebagai reservoir utama. Air yang ditampung berasal dari SBT Bribin dengan teknologi mikro-hidro turbin pompa. Pemompaan air ke RB-2 melalui pipa transmisi yang terdapat pada shaft. Kedalaman shaft dari muka tanah sampai ke SBT Bribin $+102 \mathrm{~m}$. Pendistribusian air dari RB-2 ke konsumen dengan sistem jaringan distribusi air bersih baru. Outflow dari RB-2 ke R4, R-5 dan R-8 dengan pertimbangan yaitu bila ditinjau dari elevasi antara RB-2 dengan elevasi R-4, R-5 dan R-8, maka dapat dilakukan cara gravitasi. Jarak RB-2 ke 3 reservoir tersebut relatif dekat dan kondisi lahan tempat rencana jaringan pipa, tidak begitu sulit.

Sistem jaringan distribusi air bersih yang baru berupa penggabungan antara jaringan distribusi air bersih dari reservoir baru di RB-2 ke R-4, R-5 dan R-8 yang menggunakan cara gravitasi dengan jaringan distribusi air bersih lama yang masih digunakan. Distribusi air yang lama masih menggunakan pompa dan booster pump. Dan dari hasil analisis dengan routing bahwa untuk dapat melayani semua konsumen +75.000 orang maka RB-2 memerlukan debit inflow minimum $86 \mathrm{l} / \mathrm{dt}$. Bila debit minimum ke RB-2 $65 \mathrm{l} / \mathrm{dt}$ baru dapat melayani $65 \%$ dari kebutuhan air total. Sedangkan untuk debit inflow minimum $82 \mathrm{l} / \mathrm{dt}$ baru dapat melayani $91 \%$ kebutuhan air total. Hasil perhitungan debit inflow minimum maupun debit outflow pada RB-2 yang digunakan untuk menganalisis, didasarkan pada sistem jaringan distribusi air bersih baru alternatif 2. Debit outflow RB-2 yang terdistribusi ke R-4, R-5 dan R-8, adalah sebesar 30 1/dt,27 1/dt dan 19 1/dt. Volume R-6 yang tersedia sebesar $210 \mathrm{~m} 3$ tidak mampu untuk melayani konsumen dari R-6 sendiri dari R-7 dan R-9. Maka volume R-6 diperbesar menjadi 305 m3. Demikian juga dengan volume R-4 yang tersedia sebesar $153 \mathrm{~m} 3$ tidak mampu untuk melayani konsumen dari R-4 sendiri dan dari R-6. Maka volume R-4 diperbesar menjadi $362 \mathrm{~m} 3$. 


\section{DAFTAR PUSTAKA}

Ackerman, Edward A., and George O. Lof: "Technology in American Water Development" Johns Hopkin Press, Baltimore, 1959

Anonim. 2004. Undang-Undang No.7 Tahun 2004. Tentang Sumber Daya Air, Bandung : Citra Ambara.

Agus, F,. N. Sinukaban. A. N. Ginting. H. Santoso dan Sutadi. 2007. Bunga Rampai Konservasi Tanah dan Air. Penerbit Pengurus Pusat Masyarakat Konservasi Tanah dan Air Indonesia 2004-2007. Jakarta.

Arsyad, S,. 1989. Konservasi Tanah dan Air. IPB Press. Bogor.

Asdak, C., 1995. Hidrologi dan Pengelolaan Daerah Aliran Sungai. Penerbit Gadjah Mada University Press. Yogyakarta.

Bambang Soenarto. 2002. Hidrologi Karst Keluaran Air Sungai Bawah Tanah, Mata Air dan Air Tanah di Daerah Karst Tuban. Jurnal Penelitian dan Pengembangan Pengairan, Volume 16 No. 49, Desember 2002.

Bowles, J.E. 1989. Sifat-sifat Fisis dan Geoteknis Tanah, Jakarta : Erlangga.

Biswas, Asit K.: “ A History of Hydrology,” North Horland Publishing Company, Amsterdam, 1970.

Cay Asdak. 1995. Hidrologi dan Pengelolaan DAS, Yogyakarta : Gajah Mada University.

Cahyo, Na. dan Sudarmadji. 2005. Kualitas Air Goa-Goa Karst di sekitar cekungan Wonosari (studi kasus), Wonosari

Chadwich, A. \& Morfect, J. 1993. Hydraulics in civil and Environmental Engineering, Published by E \& FN. Spon, an imprint of Chapman \& Hall, 2-6 Boundary Row, London SE 1, 8 HN, UK.

Coskun, H.G,. C. Arganei. and G. F Usta. 2008. Analysis of Land Use Change and Urbanization in the Kaculcekmece Water Rasin (Istanbul, Turkey), with Temporal Satelitte Data Using Remote Sensing and GIS Sensors 8, 72137223.

Chow, Ven Te (Ed.):"Handbook of Applied Hydrology," McGraw-Hill, New York, 1964

Finch, James K.: "Engineering and Western Civilization," McGraw-Hill, New York, 1951

George Flower, and R locas,”Wasori of Hydrology,'Beatch of Hydrology Resources, Univ Lowa, Lowa City, Lowa, 1957

Huberty, Martin R, and Warren L. Flock:"Natural Resources," McGraw-Hill, New York, 1959

Kappler, J. 2003. Water Resources Management of an Underground River in a karst area in Gunung Kidul, Seminar and Lecture, Surakarta, UNS.

Langbein W B, and W G Hoyt, “ Water Fatcts For The Nation's Future,” Ronald, New York, 1959

Mardenger, Charles J. : Civil Eangineering through the Ages, Tran ASCE, Vol CT, pp.1-27,1953 "The Nation's Water Resources", U.S Water Resources Council, Wachington DC, 1968

NSPM, Kimpraswil. 2002. Pedoman/petunjuk Teknik dan Manual (Sistem Penyediaan Air Minum Pedesaan), Departemen Permukiman dan Prasarana Wilayah, Jakarta.

Nur Yuwono. 1984. Hidrolika I, Yogyakarta : PT. Hanindita (80-83)

Rown Thoer, "Hydraulics in the United States 1776-1976," Hydrology Resources, University of Iowa, Iowa City, Iowa, 1976

RJ, Kodoatie. 2005. Pengantar Manajemen Infrastruktur, Yogyakarta : Pustaka Pelajar.

Shiklomanov, Igor A. 1993. "World Fresh Water Resources", In Water Crisis A Guide to The World Fresh Water Resources, edited by Peter H. Gleick. New York, Oxford University Press

Sofyan, I., 2004. Percentage of Total Impervious Area (PTIA) sebagai Salah Satu Faktor Penting Dalam Perencanaan Tata Ruang DAS.

Subratayati, 2008. Kajian Tentang Pengembangan Sumber Daya Air Sungai Bawah Tanah Bribin di Kecamatan Semanu Kabupaten Gunung Kidul, Daerah Istimewa Yogyakarta.

Sumarmo, LG., 2000. Konsep Usaha Tani Ramah Lingkungan. Puslitbangtan, Bogor.

Suriawiria., Unus. 2003. Air dalam Kehidupan dan Lingkungan yang Sehat. Penerbit Alumni. Bandung.

Suripin. 2001. Pelestarian Sumber Daya Tanah dan Air, Yogyakarta : Audi.

Sullivan, Caroline. 2002. "Calculating a Water Poverty Index", World Development 30

Tafangenyasha, C., and T. Dzinomwa. 2005. Land-use Impact o River Water Quality in Lowveld Sand River System in South-East Zimbabwe. Land-use and Water Resource.

Tewar, G, R., and M. Donnely: Social and Water Economy of the Pufeblo Southwest, Sci Monthly, Vol. 56, pp.31-34, Januariy, 1943, pp.134-144" Water, February, 1943.

"Water Policies for the Future", Report of the U.S. National Water Committee, Wachington DC, 1973.

"Water Resources Activities in the United States", Snate Select Committee on Nation Water Resources, United States, 1961.

White, W.B. \& White, E.L. 1989. Karst Hydrology, Van Nostrand Reinhold, 115 Fifth Avenue New York 2003. 